Lemus, B.A., Mercado, F., Bryars, T., Mouttapa, M., Conkey, T., Robertson, T. / Californian Journal of Health Promotion 2016, Volume 14, Issue 3, 64-69.

\title{
Reflections Regarding the Social Ecological Model to Address Obesity in Southern California Youth
}

\author{
Brittany A. Lemus ${ }^{1,2}$, Faviola Mercado ${ }^{1,2}$, Tracy Bryars ${ }^{2}$, Michele Mouttapa ${ }^{1}$, Tracy Conkey ${ }^{3}$, \\ and Trina Robertson ${ }^{3}$ \\ ${ }^{1}$ California State University, Fullerton, Department of Health Sciences \\ ${ }^{2}$ St. Jude Medical Center, Healthy Communities Initiative \\ ${ }^{3}$ Dairy Council of California
}

\begin{abstract}
Childhood overweight and obesity has been a significant public health concern in the United States for decades. School-based obesity prevention programs have been one strategy to address this issue. This article describes the implementation of a knowledge-based, healthy eating intervention delivered to $4^{\text {th }}$ and $5^{\text {th }}$ graders in a southern California school district. Trained graduate students implemented a nutrition education curriculum, consisting of three monthly lessons that would eventually be utilized and sustained by the schools' Physical Education (PE) teachers in the following school year. As such, the intervention drew upon the Social Ecological Model (SEM) to describe how nutrition education could be implemented in a sustainable way to future generations of youth. Students were assessed on their knowledge and dietary behaviors at pre-test and after the final lesson. Students' overall nutritional knowledge significantly increased from pre-test to post-test; however their self-reported eating behaviors (e.g., low fruit and vegetable consumption, and high consumption of chips, soda, and sweets) largely remained the same. Although the findings of this study were largely non-significant, we conclude that future interventions, which creatively address different levels of the target population's environment, may have promise if they are sufficiently dosed.

(C) 2016 Californian Journal of Health Promotion. All rights reserved. Keywords: children, overweight, obesity, nutrition education, social ecological model

\section{Introduction}

With overweight and obesity steadily on the rise in the United States, the pediatric obesity rate is quickly following suit. According to the Centers for Disease Control and Prevention (CDC), approximately $17 \%$ of children between the ages of 2-17 years are obese in the United States (CDC, 2016). This does not include children who are overweight. According to the California Department of Public Health (CDPH), 21\% of children between the ages of 2-19 years in California are obese, which is $4 \%$ higher than the rest of the nation (CDPH, 2014). My method of addressing this issue, as part of a culminating project for my MPH degree, was a knowledgebased, healthy eating intervention delivered to $4^{\text {th }}$ and $5^{\text {th }}$ graders in a southern California school district. This study was implemented by support from the St. Jude Medical Center Healthy Communities Initiative. The goal of the

Healthy Communities Initiative is to strengthen and/or develop city, school and organizational policies, systems, infrastructure, and programs that promote sustainable healthy lifestyles and result in an increase in healthy weight for both children and adults in southern California (www.stjudemedicalcenter.org).

The concept of the intervention described here draws upon the Social Ecological Model (SEM) as a framework to describe how nutrition education lessons could be implemented in a sustainable way in the targeted population. The major premise of the SEM is that individual behavior is not only a function of personal characteristics, but also characteristics of one's everyday environment. These environmental characteristics exist in layers: intrapersonal (e.g., individual-level biological and psychological traits), interpersonal (e.g., social networks and
\end{abstract}


Lemus, B.A., Mercado, F., Bryars, T., Mouttapa, M., Conkey, T., Robertson, T. / Californian Journal of Health Promotion 2016, Volume 14, Issue 3, 64-69.

cultural norms), organizational (e.g., schools), community (e.g., City Parks and Recreation Departments), environment, and policy. The SEM can be used to explain behaviors that prevent obesity. For example, improving the physical environment (e.g., providing access to public parks and safe walking environments) could be the most helpful improvement to residents who are less likely to be active (Ding et al., 2012).

The basis of my study was that altering the school environment could potentially influence children's healthy eating choices. The research team and I attempted to accomplish this endeavor by teaching children a nutrition education curriculum that would eventually be utilized and sustained by their Physical Education (PE) teachers in the following school year. For this study, we examined whether the implementation of our nutrition education curriculum was followed by significant changes in an intrapersonal factor - specifically increased nutrition knowledge. Secondly, it was assumed that increases in nutrition knowledge would accompany increases in healthy eating behaviors, as the Health Belief Model would suggest (Orji, Vassileva, \& Mandryk, 2012). I was hoping to witness my students improving their eating behaviors from pre-test to post-test, as I was determined to enact real, sustainable change during the intervention. If my hopes ended up to have statistical evidence to back it up, then training the schools' PE teachers how to implement the nutrition education lessons could make our efforts sustainable over the long term.

\section{The Healthy Eating Intervention}

Under the Healthy Communities Initiative, I coinstructed nutrition education lessons to twelve Title I and non-Title I elementary schools in one of my local school districts. Title I schools have their designation due to their relatively higher rates of children from low-income families; Title I schools receive financial assistance under the Elementary and Secondary Education Act (ESEA), to increase the likelihood that all children meet the state's academic standards (U.S. Department of Education, 2015). Given our budget and available support, we decided that conducting the study in four schools was economically and logistically feasible. Therefore, we conducted our evaluation study on four of the 12 schools to which we delivered lessons. We purposely selected two Title 1 schools and two non-Title 1 schools based on the similar size of their student body and the administration's willingness and commitment to achieving the goals of the study. We sampled schools in this manner so that we could determine whether intervention effects might have varied according to the socioeconomic characteristics of the student body.

Each of the three 50-minute lessons I instructed included discussions, games, and physical activities that taught students about the importance of eating foods from all five food groups (grains, fruits, vegetables, protein, and dairy), the benefits of the key nutrients they provide, and appropriate serving sizes. At the beginning and conclusion of the 12-week program (one lesson per month for three months), we implemented self-reported surveys. Items in these surveys came from the School Physical Activity and Nutrition (SPAN) validated questionnaire, and were used to assess the self-reported eating behaviors of 4th and 5th graders in our population of 313 students (Thiagarajah et al., 2008). Particularly, we examined students' self-reported consumption of food groups from the previous day, including fruits and vegetables (raw or prepared in a variety of different ways), and extra foods (including chips, soda, and sweets). It should be noted that extra foods, also referred to as EDNP (Energy-Dense, Nutrient Poor) are considered to be dense in energy and low in any nutritional value (Rangan, Schindeler, Hector, Gill, \& Webb).

Teaching these nutrition lessons proved to be both an exciting and challenging opportunity for me, because I was able to lead back-to-back nutrition lessons during which I taught large groups of up to 60 students per session. It was an incredibly rewarding experience to teach these lessons to students from such varied backgrounds. For some children the information they received proved to be completely new and uncharted territory, as some of them did not even know what the different food groups are. I 
Lemus, B.A., Mercado, F., Bryars, T., Mouttapa, M., Conkey, T., Robertson, T. / Californian Journal of Health Promotion 2016, Volume 14, Issue 3, 64-69.

personally feel that most students benefitted to some degree from this intervention.

\section{Study's Findings}

Even though students' overall nutritional knowledge significantly increased from an average of 8.3 questions answered correctly out of 17 at pre-test $(\mathrm{SD}=2.5)$ to 9.6 questions answered correctly at post-test $(\mathrm{SD}=2.9 ; \mathrm{p}$ $<.001$ ), their self-reported eating behaviors stayed the same, and in some instances even trended toward less healthy eating behaviors (e.g., eating more extra foods). Pre-test results showed that healthy food consumption was low even at the beginning of the study. MyPlate recommendations for children are 3 vegetable servings per day (United States Department of Agriculture, 2016), yet our students reported eating only 1 vegetable serving per day, on average. This was despite the fact that that the Healthy Communities Initiative for the Move More, Eat Healthy Campaign had been in place for over 18 months in the communities of our study schools. While extra foods should be minimally consumed, our students indicated that they were averaging 3-4 servings per day. These findings were similar for students of both Title 1 and non-Title 1 schools. Here apparently, intrapersonal changes (e.g., increases in knowledge) did not translate to behavior change (e.g., increased consumption of healthy foods). Overall, the study did not generate any significant findings in regard to improving healthy eating behaviors, and the lack of a positive intervention effect was a little bit disappointing.

While looking at other patterns in the data that were part of our original hypotheses, we found that on average, Title 1 students reported eating one more "extra foods" serving per day compared to non-Title 1 schools. It seemed as though the consumption of extra foods is not an equal opportunist among our students. This finding has very high practical significance, because consuming just one more extra food per day for a child can put him or her at a significantly higher risk for developing overweight and obesity (Petrunoff, Wilkenfeld, King, \& Flood, 2012; Rangan, Kwan, Flood, Louie, \& Gill, 2008).
We were left wondering, what happened? The intervention may not have involved enough hours (only 3 hours in total, over a span of 12 weeks) to have had a positive effect on student behavior. Nutrition education research indicates that 50 hours of intervention are required to reach behavioral change (Foster et al., 2008; Hoelscher, 2002).

It could have also been the parents. Parents are considered an important interpersonal factor in the SEM. This is because they may positively affect their children's dietary behaviors by acting as gatekeepers of the pantry, ensuring that their children eat more servings of fruits and vegetables and fewer servings of extra foods (Larsen et al., 2015). About a year before these students were surveyed, the Healthy Communities Initiative conducted self-report surveys that were distributed to parents. Of the $3,000+$ parents who responded to the survey (approximately a $15 \%$ response rate), the majority of them reported eating only 2-3 servings of fruits plus vegetables combined per day. This is despite the fact that over 6 out of 7 of these parents surveyed believed that they had "easy" or "very easy" access to fresh and affordable fruits and vegetables. In contrast, MyPlate recommendations suggest that men and women should consume at least 4-5 one-cup servings of fruits plus vegetables per day (United States Department of Agriculture, 2016). Taking the survey results of the children in my MPH project and the parents a year ago, it seems as though children's low consumption of fruits and vegetables resemble that of their parents. Furthermore, the fact that Title 1 and non-Title 1 students had similar levels of fruit and vegetable intake suggests that socioeconomic status is not a significant factor, at least in our study locations.

Some might question the validity of our findings due to self-report bias or inaccurate recall, especially given that the students surveyed were $4^{\text {th }}$ and $5^{\text {th }}$ graders. For example, self-report bias might lead us to conclude that some students over-reported their vegetable consumption, while under-reporting their consumption of extra foods. Even taking these methodological flaws into consideration, it does indicate that student 
Lemus, B.A., Mercado, F., Bryars, T., Mouttapa, M., Conkey, T., Robertson, T. / Californian Journal of Health Promotion 2016, Volume 14, Issue 3, 64-69.

food choices, even after three nutrition education lessons, mirror the national averages for low fruit and vegetable intake and high extra calorie foods (Steele et al., 2016).

\section{Conclusion}

At the end of this study, the research team was left wondering, where do we go from here? Here is what we came up with: First, if we are going to evaluate our nutrition education intervention again, we need to "beef up its dosage" by increasing the number of lessons. My MPH classmate and I have already created three additional lessons for the intervention, for a total of six lessons. Although the amount of intervention time that these six lessons cover is not anywhere near the recommended 50 hours of intervention to reach behavioral change (Foster et al., 2008; Hoelscher, 2002), it is a step in the right direction.

Our second conclusion is to not give up on the SEM. Just because one intervention did not work at one particular level (e.g., the school level), it does not mean that other interventions addressing different levels of the target population's environment will not work. The fact that both students and parents in the schools we have surveyed (the former in this study and the latter in a previous evaluation we conducted) consume relatively few fruits and vegetables on a daily basis suggest to us that a parent-level intervention may have some promise. In the upcoming year, the Healthy Communities Initiative will be conducting cooking demonstrations at food pantries, in the hopes that parents of families of low-income households will discover nutritious, delicious, low-prep, and low-cost meals and snacks they can serve their children. This strategy is consistent with the Initiative's Move More, Eat Healthy Campaign that was created to support and facilitate nutrition education in low-income populations at various sites. Beets, Swanger, Wilcox, and Cardinal (2007) found that their cooking demonstrations were positive in that they increased awareness of nutrition and decreased negative attitudes toward healthy eating (Beets, Swanger, Wilcox, \& Cardinal, 2007).
The Healthy Communities Initiative will also continue to increase awareness and promote healthy nutrition through social media - which belongs to the community layer of the SEM. The social media component of the Initiative has increasingly grown, with over 1,000 Facebook, Instagram, and Twitter followers combined.

In an attempt to reach the schools a second time, the Healthy Communities Initiative is also supporting the implementation of the Smarter Lunchroom Movement in the school district where I conducted my study. The premise behind the Smarter Lunchroom Movement is that making low-cost aesthetic modifications to the school cafeteria can facilitate students choosing and consuming healthier food options, compared to the less healthy food options available (http://smarterlunchrooms.org/homepage). For example, one Smarter Lunchroom Movement strategy is to place white milk in front the chocolate milk, so that students are more likely to pick up the white milk as a result (Hanks, Just, Smith, \& Wansink, 2012).

Creating a culture of health that provides an environment where healthy nutrition and physical opportunities are the easy choices to make at home, school, work, and during play will support our goal in creating a healthier community. Even though pediatric obesity is on the rise, the bottom line is not to give up. It is vital to persist in our goal of preventing pediatric obesity when children are still forming their eating habits. Keeping the SEM in the forefront of our creative thinking may result in future innovations that might operate at different levels. We can continue to expand our collaboration with various sectors of the communities we serve, harnessing our combined strengths to produce a healthier and happier generation of children in California.

\section{Disclaimer}

The opinions expressed in this editorial are my own and do not necessarily reflect the opinions of California State University, Fullerton, St. Jude Medical Center, or the Dairy Council of California. 
Lemus, B.A., Mercado, F., Bryars, T., Mouttapa, M., Conkey, T., Robertson, T. / Californian Journal of Health Promotion 2016, Volume 14, Issue 3, 64-69.

\section{References}

Beets, M.W., Swanger, K., Wilcox, D.R., \& Cardinal, B.J. (2007). Using hands-on demonstrations to promote cooking behaviors with young adolescents: The culinary camp summer cooking program. Journal of Nutrition Education and Behavior, 39(5), 288-289. doi: 10.1016/j.jneb.2007.05.002

California Department of Public Health, Nutrition Education and Obesity Prevention Branch. (2014). Obesity in California: The weight of the state, 2000-2012. Retrieved from: https://www.cdph.ca.gov/programs/cpns/Documents/ObesityinCaliforniaReport.pdf

Centers for Disease Control and Prevention. (2016, October 18). Prevalence of childhood obesity in the United States, 2011-2012. Retrieved from: http://www.cdc.gov/obesity/data/childhood.html

Ding, D., Sallis, J. F., Conway, T. L., Saelens, B. E., Frank, L. D., Cain, K. L., \& Slymen, D. J. (2012). Interactive effects of built environment and psychosocial attributes on physical activity: a test of ecological models. Annals of Behavioral Medicine, 44, 365-374.

Foster, G. D., Sherman, S., Borradaile, K. E., Grundy, K. M., Vander Veur, S. S., \& Nachmani, J. (2008). A policy-based school intervention to prevent overweight and obesity. Pediatrics, 121, 794-802. doi: 10.1542/peds.2007-1365

Hanks, A.S., Just, D.R., Smith, L.E., \& Wansink, B. (2012). Healthy convenience: nudging students toward healthier choices in the lunchroom. Journal of Public Health Advance Access, 34(3), 360-6. doi: 10.1093/pubmed/fds003

Hoelscher, D. M., Evans, A., Parcel, G. S., \& Kelder, S. H. (2002). Designing effective nutrition interventions for adolescents. The American Dietetic Association, 102(3), S52-S63.

Larsen, J.K., Hermans, R.C., Sleddens, E.F., Engels, R.C., Fisher, J.O., Kremers, S.P. (2015). How parental dietary behavior and food parenting practices affect children's dietary behavior. Interacting sources of influence? Appetite, 89, 246-57. doi: 10.1016/j.appet.2015.02.012.

Orji, R., Vassileva, J., \& Mandryk, R. (2012). Towards an effective health interventions design: An extension of the health belief Model. Online Journal of Public Health Informatics, 4(3). doi:10.5210/ojphi.v4i3.4321

Petrunoff, N.A., Wilkenfeld, R.L., King, L.A., Flood, V.M. (2012). 'Treats', 'sometimes foods', 'junk': a qualitative study exploring 'extra foods' with parents of young children. Public Health Nutrition, 17(5), 979-986. doi:10.1017/S1368980012005095

Rangan, A.M., Kwan, J.S.L., Louie, J.C.Y., Flood, V.M., \& Gill, T.P. (2011). Changes in core food intake among Australian children between 1995 and 2007. European Journal of Clinical Nutrition, 65, 1201-1210. doi: 10.1038/ejen.2011.109

Rangan, A.M., Randall, D., Hector, D.J., Gill, T.P., \& Webb, K.L. (2010). Consumption of 'extra' foods by Australian children: types, quantities and contribution to energy and nutrient intakes. European Journal of Clinical Nutrition, 62(3), 356-364. doi:10.1038/ejen.2008.51

Steele, E.M., Galastri, L., da Costa Louzada, M.L., Moubarac, J.C., Mozaffarian, D., \& Monteiro, C.A. (2016) Ultra-processed foods and added sugars in the US diet: Evidence from a nationally representative cross-sectional study. BMJ Open 2016;6:e009892. doi:10.1136/bmjopen-2015-009892

Thiagarajah K., Fly A.D., Hoelscher D.M., Bai Y., Lo K., Leone A., \& Shertzer J.A. (2008). Validating the food behavior questions from the elementary school SPAN questionnaire. Journal of Nutrition Education and Behavior, 40(5):305-310. doi:10.1016/j.jneb.2007.07.004. 
Lemus, B.A., Mercado, F., Bryars, T., Mouttapa, M., Conkey, T., Robertson, T. / Californian Journal of Health Promotion 2016, Volume 14, Issue 3, 64-69.

United States Department of Agriculture (2016). MyPlate. Retrieved from https://www.choosemyplate.gov/MyPlate

United States Department of Education. (2015, October 5). Improving basic programs Operated by local educational agencies (Title I, Part A). Retrieved from: http://www2.ed.gov/programs/titleiparta/index.html

\author{
Author Information \\ Michele Mouttapa, $\mathrm{PhD}^{*}$ \\ mmouttapa@fullerton.edu \\ Office: 657-278-3980
}

*Corresponding Author 